Ann. Biol. anim. Bioch. Biophys., 1977, 17 (1), 71-83.

\title{
Influence de la nature des protéines alimentaires sur la composition en acides aminés des fèces du veau préruminant
}

\author{
par P. PATUREAU-MIRAND, R. TOULLEC *, P. GUILLOTEAU *, R. PION \\ a vec la collaboration technique de Yvette LENTO ef Marie-Claude VALLUY \\ Laboratoire d'Etude du Métabolisme Azoté \\ I.N.R.A., Theix, 63110 Beaumont \\ * Station de Recherches Zootechniques \\ I.N.R.A., 65, rue de Soint Brieuc, 35042 Rennes Cedex
}

Summary. Effect of type of milk-replacer protein on amino acid composition of preruminont calf feces.

Seven experimental proteins are tested in the following milk-replacers : milk (« lait») milk-replacer : 100 p. 100 spray-dried milk ; fish (« poisson ») milk-replacer : 81 p. 100 fish protein concentrate, 19 p. 100 whey; soya protein concentrate (« soja concentré ») milk-replacer : 78 p. 100 soya protein concentrate, 22 p. 100 whey ; fermented soya (« soja fermenté ») milk-replacer : 77 p. 100 fermented soya meal protein, 23 p. 100 whey ; horsebean (« féverole») milk-replacer : 73 p. 100 horse bean protein concentrate, 27 p. 100 whey ; potato (《 pomme de terre ») milk-replacer : 75 p. 100 potato protein concentrate, 25 p. 100 whey ; yeast (《 levures ») milk-replacer : 50 p. 100 alkane yeast protein, 50 p. 100 spray-dried milk protein and whey. Each milk-replacer, except the fermented soya and milk milk-replacers, is given for at least one month to 3 Friesian male calves. The fermented soya and milk milk-replacers are given to 6 calves (table 3). Feces are collected for 5 days (milk milk-replacer), 6 days (yeast milk-replacer) or 11 days (other replacers). The feces are frozen and stored at $-15^{\circ} \mathrm{C}$ before freeze-drying and analysis. The amino acid contents of the experimental proteins and feces are determined by ion-exchange chromatography on an automatic analyser.

The amino acid content of the feces of the preruminant calves fed these milk-replacers are high in threonine, serine, cystine, glycine and alanine; they are low in histidine (table 4). The apparent digestibility of cystine, glycine and alanine is lower than the other amino acids (table 5). There is a significant difference between the protein amino acid composition of the milk milk-replacer and that of the feces of calves fed this replacer. This difference is also large when soya protein concentrate and yeast milk-replacers are given. The smallest difference is found with the potato replacer (table 7). This suggests that true protein digestibility of the milk, soya concentrate and yeast milk-replacers is high, whereas that of the potato milk-replacer is lowest. The amino acid composition of the feces of calves fed the milk milk-replacer are similar to those of piglets given a protein-free diet or one containing 4 p. 100 egg protein. This indicates that preruminant calf fecal protein is mostly endogenous and microbial. A tentative estimation of the amount of endogenous and microbial protein excreted in the feces shows it to be highest in calves fed soya concentrate, fermented soya and horse-bean milk-replacers ; it is lowest in those fed milk and potato milk-replacers. 


\section{Introduction.}

De nombreux travaux, rappelés dans 2 revues bibliographiques récentes (Toulec et al., $1973 ; 1975)$ ont été consacrés à la détermination du coefficient d'utilisation digestive de l'azote chez le Veau préruminant, en vue d'apprécier l'utilisation digestive des protéines de remplacement des aliments d'allaitement. En revanche, il existe peu d'études chez le Veau, concernant l'influence de la nature des matières azotées alimentaires sur la composition en acides aminés des fèces et sur la digestibilité réelle ou apparente des acides aminés (Radostits et Bell, 1968 ; Van Weerden, 1974). Cependant des travaux comparables ont été effectués chez le Rat (Kuiken et Lyman, 1948 ; Hepburn, Calhoun et Bradley, 1966 ; de Muelenaere, Chen ef Harper, 1967 ; Poppe,

\section{TABLEAU 1}

Composition des aliments (p. 100 de l'aliment)

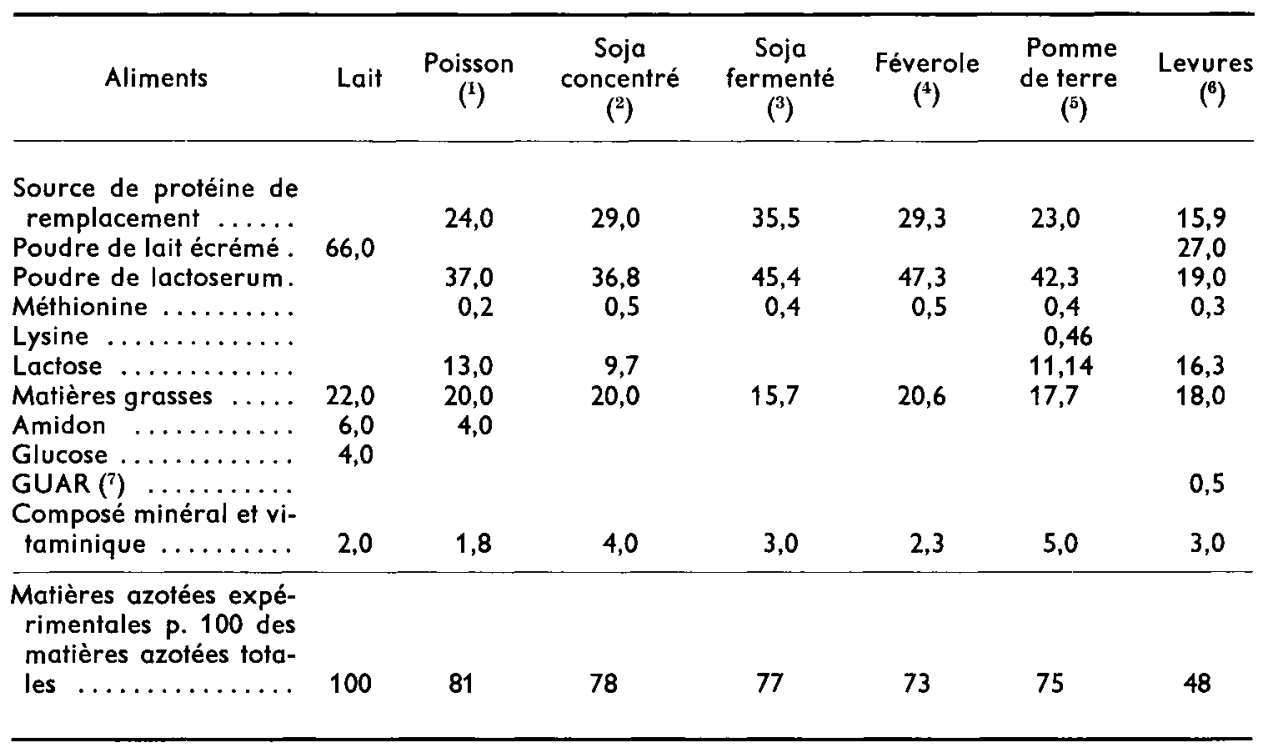

(1) Farine de poisson de Norvège délipidée par extraction à l'hexane ef finement broyée (taille moyenne des particules : $35 \mu$ ) (NORSILDMEL, 5001, Bergen, Norvège).

${ }^{2}$ ) Tourteau de soja traité par la chaleur humide et concentré en protéines par extraction éthanolique du saccharose et des oligosaccharides (HAYPRO-T, HAYES Ltd, Ashood, Israel).

( $\left.{ }^{3}\right)$ Tourteau de soja débarrassé de son saccharose et de ses oligosaccharides par fermentation par Geotrichum condidum (T. Staron, Laboratoire des antibiotiques, INRA, Chartres et S.I.C.A. Europrotéines, 16, rue d'Inkermann, 79000 Niort).

$\left.{ }^{4}\right)$ Obtenu à partir de graines de féverole par extraction aqueuse à $\mathrm{pH} 8,5$, élimination de la majeure partie des constituants insolubles par décantation et séchage par le procédé Spray (J. Culioli ef D. Le Douaron, Laboratoire de Recherches de Technologie Laitière, INRA, Rennes).

$\left({ }^{5}\right)$ Sous-produit de la féculerie (AVEBE, Benden Oosterdiet, 27 Veendam, Pays-Bas).

(6) Levures d'alcanes cultivées sur gas-oil (Société Française des Pétroles BP, 10, quai Paul-Doumer 92401 Courbevoie).

(7) Agent facilitant le maintien en suspension des produits insolubles (IRANEX S.A., 4, rue frédéric-Passy, 92200 Neuilly-sur-Seine). 
Meier et Uhlemann, 1971, Eggum, 1973) et chez le Porc (Dammers, 1964 ; Poppe, Meier etWiesemuller, 1970 ; Carlson et Bayley, 1970 ; Eggum, 1973 ; ?Pastuszewska ef al., 1974 ; Mason, Just, Bech-Andersen, 1976) pour mesurer l'absorption ef la disponibilité des acides aminés des protéines alimentaires. Aussi avons-nous déterminé la composition en acides aminés des fèces des veaux recevant les aliments d'allaitement étudiés par Guilloteau ef al. (1976) et Toullec (travaux en cours) de façon à préciser l'importance de certains facteurs qui contrôlent l'utilisation digestive des protéines alimentaires.

\section{Matériel et méthodes.}

\section{1) Aliments.}

Sept aliments d'allaitement (tabl. 1) contenant environ 25 p. 100 de matières azotées par rapport à la matière sèche, sont utilisés. Dans l'aliment témoin (aliment Lait), les protéines proviennent exclusivement du lait écrémé. Dans l'aliment Levures,

TABLEAU 2

Teneur en matières azotées $\left(^{1}\right)(\mathrm{g} \mathrm{p} .100 \mathrm{~g}$ de matière sèche) ef composition en acides aminés ( $\mathrm{g}$ P. $16 \mathrm{~g}$ d'azote) des aliments $\left({ }^{2}\right.$ )

\begin{tabular}{|c|c|c|c|c|c|c|c|}
\hline Aliments & Laif & Poisson & $\begin{array}{c}\text { Soja } \\
\text { concentré }\end{array}$ & $\begin{array}{c}\text { Soja } \\
\text { fermenté }\end{array}$ & Féverole & $\begin{array}{l}\text { Pomme } \\
\text { de terre }\end{array}$ & Levures \\
\hline $\begin{array}{l}\text { Matières azotées } \\
(N \times 6,25) \ldots \ldots\end{array}$ & 24,8 & 26,6 & 24,8 & 26,9 & 24,2 & 26,8 & 24,2 \\
\hline 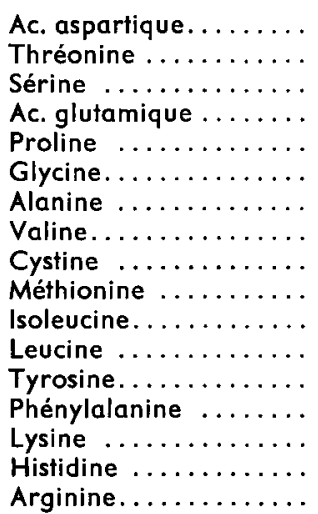 & $\begin{array}{c}7,9 \\
4,6 \\
5,8 \\
22,6 \\
9,9 \\
2,0 \\
3,5 \\
7,15 \\
0,9 \\
2,6 \\
5,75 \\
10,0 \\
5,1 \\
5,35 \\
8,5 \\
2,9 \\
3,55\end{array}$ & $\begin{array}{l}8,35 \\
4,4 \\
4,0 \\
13,3 \\
4,6 \\
5,0 \\
5,35 \\
5,25 \\
0,95 \\
3,5 \\
4,45 \\
6,95 \\
2,65 \\
3,55 \\
6,7 \\
2,7 \\
4,5\end{array}$ & $\begin{array}{c}11,15 \\
4,4 \\
5,1 \\
18,65 \\
5,6 \\
3,65 \\
4,2 \\
5,25 \\
1,65 \\
3,55 \\
5,05 \\
7,85 \\
3,65 \\
4,5 \\
6,35 \\
2,5 \\
5,85\end{array}$ & $\begin{array}{c}10,45 \\
4,3 \\
4,83 \\
17,05 \\
4,95 \\
3,45 \\
4,3 \\
4,8 \\
1,5 \\
3,1 \\
4,85 \\
7,8 \\
3,5 \\
4,5 \\
6,35 \\
2,3 \\
6,4\end{array}$ & $\begin{array}{c}10,15 \\
4,1 \\
4,55 \\
16,45 \\
4,5 \\
3,4 \\
3,8 \\
4,55 \\
1,25 \\
3,45 \\
4,15 \\
7,05 \\
3,05 \\
3,7 \\
5,9 \\
2,05 \\
7,15\end{array}$ & $\begin{array}{c}12,25 \\
5,9 \\
5,55 \\
12,55 \\
4,85 \\
4,7 \\
4,95 \\
7,0 \\
1,71 \\
2,3 \\
5,91 \\
10,25 \\
5,25 \\
5,9 \\
8,15 \\
2,1 \\
4,75\end{array}$ & $\begin{array}{c}8,85 \\
5,1 \\
5,3 \\
17,7 \\
6,5 \\
3,25 \\
4,75 \\
6,3 \\
1,1 \\
3,3 \\
5,5 \\
8,55 \\
4,2 \\
5,0 \\
8,05 \\
2,3 \\
4,0\end{array}$ \\
\hline $\begin{array}{l}\text { Pourcentage de l'azote } \\
\text { des acides aminés dosés } \\
\text { dans l'azote total . . . . . }\end{array}$ & 85,7 & 73,7 & 82,2 & 79,7 & 76,5 & 85,7 & 81,1 \\
\hline
\end{tabular}

(1) Déferminée par analyse.

( ${ }^{2}$ Déterminée par calcul à l'aide des résultats d'analyse de la composition en acides aminés des divers constituants protéiques de l'aliment. 
les protéines de remplacement sont apportées par des levures d'alcanes (48 p. 100), le reste étant fourni par du lait écrémé (40 p. 100) et par du lactosérum et un supplément de méthionine (12 p. 100). Dans les 5 autres aliments, qui sont dépourvus de lait écrémé, la majeure partie des protéines (75 à 80 p. 100) est constituée de protéines de remplacement : un concentré protéique de poisson, de soja, de féverole, de pomme de terre, ou un tourteau de soja fermenté, le reste étant fourni par du lactosérum et un supplément de méthionine. La composition en acides aminés de ces aliments (tabl. 2) est calculée à partir de la composition en acides aminés des différentes sources protéiques constitutives.

\section{2) Animaux ef prélèvements.}

Les aliments sont distribués depuis l'âge d'environ 2 semaines à des veaux mâles de race Frisonne, dont les caractéristiques ef les performances, enregistrées pendant les périodes de prélèvements, sont rapportées dans le tableau 3. Les animaux des diffé-

\section{TABLEAU 3}

Performances des animaux ou cours de la période de prélèvements

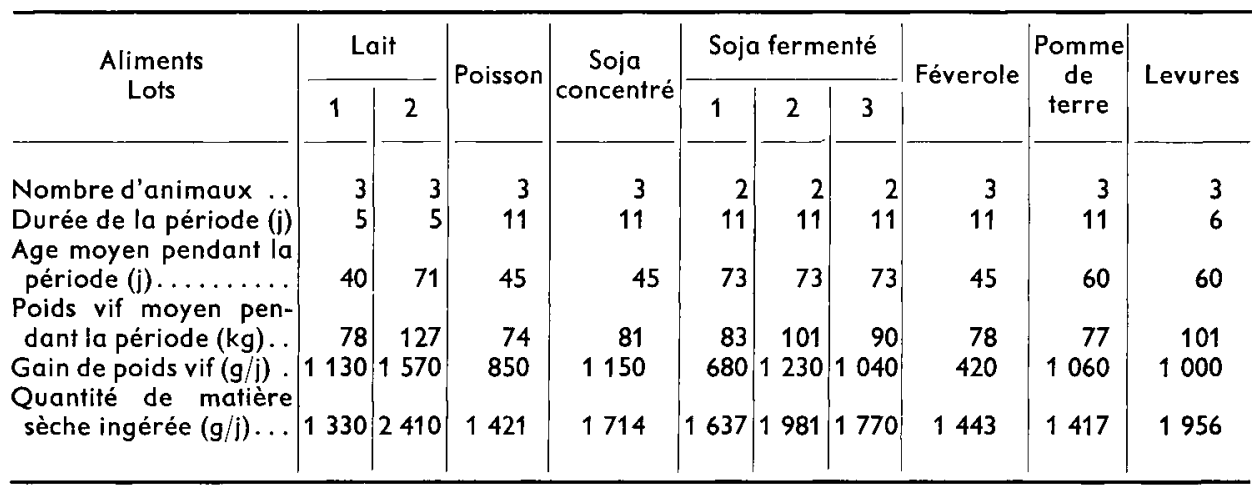

rents lots sont tous élevés en cage à bilans sur caillebotis métallique et tapis de caoutchouc, sauf ceux du lot Lait 2 qui sont logés dans des cases sur litière de copeaux. Les fèces sont collectées dans des bacs (animaux en cages à bilan) ou dans des sacs de plastique maintenus à l'aide de harnais (veaux sur litière); elles sont recueillies et congelées journellement et servent à préparer un échantillon moyen par période et par veau. Après lyophilisation, un échantillon moyen par période et par aliment est obtenu en mélangeant les échantillons individuels. Ces échantillons sont tamisés de façon à éliminer la majeure partie des poils présents dans les fèces. Dans le cas des aliments Lait et Soja fermenté, les prélèvements ont été regroupés de façon à reconstituer respectivement 2 lots de 3 veaux (Lait 1 et 2) et 3 lots de 2 veaux (Soja fermenté 1 , 2 et 3), de façon à tenter de préciser la variabilité de la composition en acides aminés des fèces chez des animaux recevant le même régime. 


\section{3) Techniques analytiques.}

L'azote des régimes et des fèces est dosé par la méthode Kjeldahl et les teneurs en acides aminés des sources protéiques et des fèces sont déterminées par la méthode décrite par Pion et Fauconneau (1966).

La comparaison de la composition en acides aminés de 2 protéines est effectuée par la détermination de leur écart relatif moyen qui est la moyenne des écarts relatifs entre les teneurs en chacun des acides aminés qui composent ces protéines. Cet écart est donc calculé de la façon suivante :

Ecart relatif moyen entre les protéines i et $j=\frac{1}{16} \sum_{k=1}^{16} \sqrt{(A A i k-A A j k)^{2}} / \frac{\text { AAik }+ \text { AAjk }}{2}$ AAik et AAjk sont respectivement le pourcentage de l'acide aminé $k$ dans la somme des teneurs en acides aminés des protéines $i$ et $j$ (à l'exception des teneurs en tryptophane, non dosé). De plus, $k$ qui représente les différents acides aminés ne varie que de 1 à 16 car nous excluons de ce calcul les pourcentages de cystine qui dépendent en partie de la quantité variable de poils retrouvée dans les fèces même tamisées. La comparaison statistique des écarts relatifs moyens est effectuée à l'aide du test $t$, protégé par un test $F$.

L'analyse par régression multiple de l'influence de la nature des protéines alimentaires de remplacement $(A)$ ainsi que de celle des protéines endogènes et microbiennes (B) sur la composition en acides aminés des fèces $(F)$ est réalisée selon la méthode décrite par Snedecor et Cochran (1971). Chacune des 3 variables A, B et $F$ prend les différentes valeurs des teneurs en chaque acide aminé $k$ des matières azotées expérimentales de remplacement, des matières azotées endogènes et microbiennes et des matières azotées fécales. Ces teneurs sont exprimées en pour cent de la somme des teneurs en acides aminés dosés dans chacune des catégories de matières azotées. La cystine et le tryptophane sont exclus du calcul de la régression pour les raisons expliquées précédemment.

\section{Résultats et discussion.}

1) Teneur en matières azotées des fèces (tabl. 4).

La teneur en matières azotées de la matière sèche des fèces des veaux nourris avec les aliments Poisson, Soja fermenté, Féverole et Pomme de terre est voisine de 40 p. 100 ; celle des fèces des veaux des lots Lait 1, Soja concentré et Levures est proche de 30 p. 100 et celle des veaux du lot Lait 2, de l'ordre de 20 p. 100. La différence observée entre les 2 lots Lait peut provenir en partie d'une dilution des matières azotées fécales par des fragments de copeaux de la litière que les animaux ingèrent malgré leur muselière.

2) Teneurs en acides aminés des fèces (łabl. 4).

L'azote des acides aminés dosés représente environ 70 p. 100 de l'azote des fèces des veaux qui ingèrent les aliments Lait, Soja fermenté et Pomme de terre. Ce pourcen- 
tage n'est plus que de l'ordre de 64 p. 100 dans les fèces des veaux nourris avec les aliments Soja concentré, Féverole et Levures. Il est inférieur à 60 p. 100 lorsque les veaux ingèrent l'aliment Poisson, ce qui est proche de la valeur observée par Eggum (1973) chez le Rat. C'est d'ailleurs dans les matières azotées de l'aliment Poisson que le pourcentage de l'azote des acides aminés (73 p. 100) est le plus faible. Il n'y a cependant pas nécessairement un lien entre ces 2 observations, car les composés azotés non protidiques (ammoniac, amines, sucres aminés, acides nucléiques en particulier) ont de grandes chances d'être métabolisés et absorbés. La variabilité de la part de l'azote des acides aminés dans l'azote total selon les aliments et les fèces indique que les coefficients d'utilisation digestive apparente moyens des acides aminés de 2 régimes qui ont le même coefficient d'utilisation digestive apparente de l'azote, pourraient être assez différents.

\section{TABLEAU 4}

Teneurs en matières azotées ( $\mathrm{g}$ p. $100 \mathrm{~g}$ de matière sèche) ef en acides aminés ( $\mathrm{g} \mathrm{p} .16 \mathrm{~g}$ d'azote) des fèces

\begin{tabular}{|c|c|c|c|c|c|c|c|c|c|c|}
\hline \multirow{2}{*}{$\begin{array}{l}\text { Aliments } \\
\text { Lots }\end{array}$} & \multicolumn{2}{|c|}{ Lait } & \multirow{2}{*}{ Poisson } & \multirow{2}{*}{$\begin{array}{c}\text { Soja } \\
\text { concentré }\end{array}$} & \multicolumn{3}{|c|}{ Soja fermenté } & \multirow{2}{*}{ Féverole } & \multirow{2}{*}{$\begin{array}{c}\text { Pomme } \\
\text { de } \\
\text { terre }\end{array}$} & \multirow{2}{*}{ Levures } \\
\hline & 1 & 2 & & & 1 & 2 & 3 & & & \\
\hline $\begin{array}{r}\text { Matières azotées }(\mathrm{N} \times \\
6,25) \ldots \ldots \ldots \ldots \ldots\end{array}$ & 29,5 & 20,4 & 41,9 & 29,4 & 37,7 & 39,2 & 35,2 & 40,7 & 38,0 & 31,7 \\
\hline 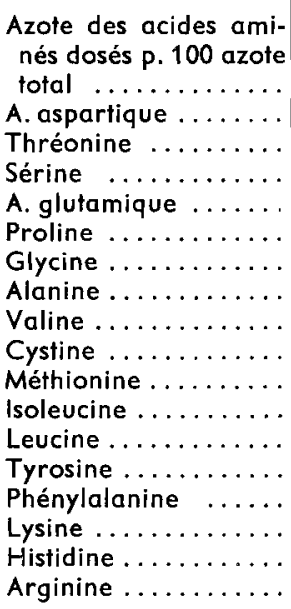 & $\begin{array}{r}67,5 \\
8,47 \\
4,24 \\
4,04 \\
10,74 \\
3,04 \\
4,20 \\
4,97 \\
5,32 \\
2,23 \\
1,92 \\
3,89 \\
6,35 \\
3,85 \\
4,09 \\
6,11 \\
1,90 \\
4,43\end{array}$ & $\begin{array}{c}72,6 \\
10,08 \\
4,81 \\
5,07 \\
11,48 \\
3,55 \\
4,74 \\
6,39 \\
5,20 \\
2,65 \\
2,41 \\
3,93 \\
6,38 \\
N D \\
N D \\
6,17 \\
1,88 \\
4,03\end{array}$ & $\begin{array}{l}57,5 \\
7,35 \\
3,98 \\
3,65 \\
9,11 \\
3,28 \\
4,29 \\
4,78 \\
4,51 \\
1,96 \\
2,13 \\
3,79 \\
5,61 \\
2,86 \\
3,57 \\
4,82 \\
1,38 \\
2,65\end{array}$ & $\begin{array}{r}62,9 \\
8,74 \\
4,36 \\
3,99 \\
10,09 \\
3,90 \\
4,77 \\
5,17 \\
4,86 \\
1,87 \\
1,88 \\
4,27 \\
6,49 \\
3,38 \\
3,96 \\
4,53 \\
1,40 \\
3,08\end{array}$ & $\begin{array}{r}71,1 \\
9,27 \\
4,33 \\
4,38 \\
12,50 \\
4,44 \\
4,37 \\
5,08 \\
5,09 \\
1,85 \\
1,54 \\
4,09 \\
7,66 \\
3,85 \\
4,86 \\
5,14 \\
1,84 \\
4,82\end{array}$ & \begin{tabular}{|r|}
76,5 \\
9,91 \\
4,46 \\
4,57 \\
13,47 \\
4,74 \\
4,73 \\
5,36 \\
5,45 \\
1,73 \\
1,78 \\
4,63 \\
8,31 \\
3,96 \\
4,86 \\
6,37 \\
1,90 \\
5,07
\end{tabular} & \begin{tabular}{|r|}
70,0 \\
9,68 \\
4,21 \\
4,09 \\
12,49 \\
3,98 \\
4,50 \\
5,21 \\
5,43 \\
1,63 \\
1,44 \\
4,57 \\
7,17 \\
3,88 \\
4,57 \\
5,23 \\
1,74 \\
4,43
\end{tabular} & $\begin{array}{r}64,3 \\
8,94 \\
3,78 \\
3,95 \\
11,78 \\
3,80 \\
3,95 \\
4,39 \\
4,34 \\
1,91 \\
1,24 \\
3,73 \\
6,68 \\
3,43 \\
4,25 \\
4,78 \\
1,72 \\
4,28\end{array}$ & $\begin{array}{l}67,6 \\
8,33 \\
4,75 \\
4,30 \\
9,61 \\
3,70 \\
5,06 \\
5,76 \\
5,76 \\
2,00 \\
1,58 \\
5,17 \\
7,57 \\
4,11 \\
5,12 \\
5,76 \\
1,45 \\
3,11\end{array}$ & $\begin{array}{r}64,5 \\
8,71 \\
4,76 \\
4,56 \\
9,46 \\
3,83 \\
5,01 \\
5,36 \\
4,77 \\
2,79 \\
2,27 \\
4,41 \\
6,71 \\
3,56 \\
3,88 \\
4,85 \\
1,33 \\
2,79\end{array}$ \\
\hline
\end{tabular}

ND : non dosé.

- Utilisation digestive apparente des acides aminés (tabl. 5).

Cependant d'une façon générale le coefficient d'utilisation dig€stive apparente moyen des acides aminés varie, selon les aliments, dans le même sens que celui de l'azote. Les coefficients d'utilisation digestive apparente des acides aminés sont rela- 
tivement voisins pour un même aliment. Cependant ceux de la cystine, de la glycine et de l'alanine sont généralement les plus faibles. Cela résulte vraisemblablement plus des particularités et de l'importance de l'azote endogène et microbien dans les fèces que d'une réelle indisponibilité de ces acides aminés dans les protéines alimentaires. En effet, la faible digestibilité apparente de la cystine pourrait s'expliquer non seulement par la présence de poils dans les fèces mais aussi de protéines endogènes riches en cystine comme le suc pancréatique, car la faible digestibilité apparente de la cystine a déjà été signalée chez le Rat (Combe, 1973 ; Pion, Mendes-Pereira, Prugnaud, 1974), le Porc (Dammers, 1964 ; Pastuszewska et al., 1974) et le Veau préruminant (Van Weerden, 1974) sans que soit mentionnée la présence de poils; la présence dans les fèces de protéines endogènes ou microbiennes plus riches en glycine et alanine que les protéines alimentaires ainsi que l'activité métabolique de l'intestin et de la flore microbienne peuvent contribuer d̀ expliquer la relativement faible digestibilité de ces acides aminés. L'emploi des coefficients d'utilisation digestive apparente des acides aminés peut paraître délicat pour apprécier la disponibilité des acides aminés alimentaires lorsque la part des matières azotées endogènes ou microbiennes dans les matières azotées fécales n'est plus négligeable. Il convient donc de tenter de mieux préciser l'origine des acides aminés fécaux.

TABLEAU 5

Coefficients d'utilisation digestive apparente de l'azote et des acides aminés

\begin{tabular}{|c|c|c|c|c|c|c|c|}
\hline Aliments & Lait & Poisson & $\begin{array}{c}\text { Soja } \\
\text { concentré }\end{array}$ & $\begin{array}{c}\text { Soja } \\
\text { fermenté }\end{array}$ & Féverole & $\begin{array}{l}\text { Pomme } \\
\text { de terre }\end{array}$ & Levure \\
\hline 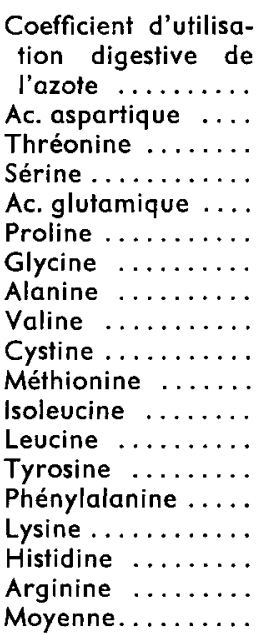 & $\begin{array}{l}95,0(1) \\
94,1 \\
95,1 \\
96,1 \\
97,5 \\
98,3 \\
88,8 \\
91,9 \\
96,3 \\
86,4 \\
95,8 \\
96,6 \\
96,8 \\
96,2 \\
96,2 \\
96,4 \\
96,7 \\
94,0 \\
94,9\end{array}$ & $\begin{array}{l}84,1\left(^{2}\right) \\
86,0 \\
85,7 \\
85,5 \\
89,1 \\
88,6 \\
86,4 \\
85,8 \\
86,4 \\
67,9 \\
90,3 \\
86,4 \\
87,2 \\
83,0 \\
84,0 \\
88,5 \\
91,8 \\
90,6 \\
86,1\end{array}$ & $\begin{array}{l}83,4\left(^{2}\right) \\
87,0 \\
83,6 \\
87,1 \\
91,0 \\
88,5 \\
78,2 \\
79,5 \\
84,6 \\
81,3 \\
91,2 \\
85,9 \\
86,3 \\
84,7 \\
85,4 \\
88,2 \\
90,7 \\
91,3 \\
86,1\end{array}$ & $\begin{array}{c}78,3\left(^{2}\right) \\
80,0 \\
78,1 \\
80,5 \\
83,7 \\
80,7 \\
71,3 \\
73,6 \\
76,0 \\
74,6 \\
89,0 \\
80,3 \\
78,6 \\
76,0 \\
77,0 \\
81,0 \\
83,0 \\
83,9 \\
79,3\end{array}$ & $\begin{array}{l}76,3\left({ }^{2}\right) \\
79,1 \\
78,3 \\
79,4 \\
83,0 \\
80,0 \\
72,3 \\
72,5 \\
77,3 \\
63,8 \\
91,5 \\
78,8 \\
77,5 \\
73,2 \\
72,9 \\
80,7 \\
80,3 \\
85,8 \\
78,0\end{array}$ & $\begin{array}{l}86,1\left(^{3}\right) \\
90,5 \\
88,8 \\
89,3 \\
89,4 \\
89,4 \\
85,0 \\
83,8 \\
88,6 \\
83,7 \\
90,4 \\
87,8 \\
89,8 \\
89,1 \\
88,0 \\
90,2 \\
90,5 \\
90,9 \\
88,5\end{array}$ & $\begin{array}{l}86,5\left(^{3}\right) \\
86,7 \\
87,4 \\
88,4 \\
92,8 \\
92,1 \\
79,1 \\
84,7 \\
89,8 \\
66,1 \\
90,7 \\
89,2 \\
89,4 \\
88,6 \\
89,5 \\
91,9 \\
92,2 \\
90,5 \\
87,6\end{array}$ \\
\hline
\end{tabular}

(1) Valeur moyenne.

(2) Guilloteau et ol., 1976.

(3) Toullec (résultats non publiés). 


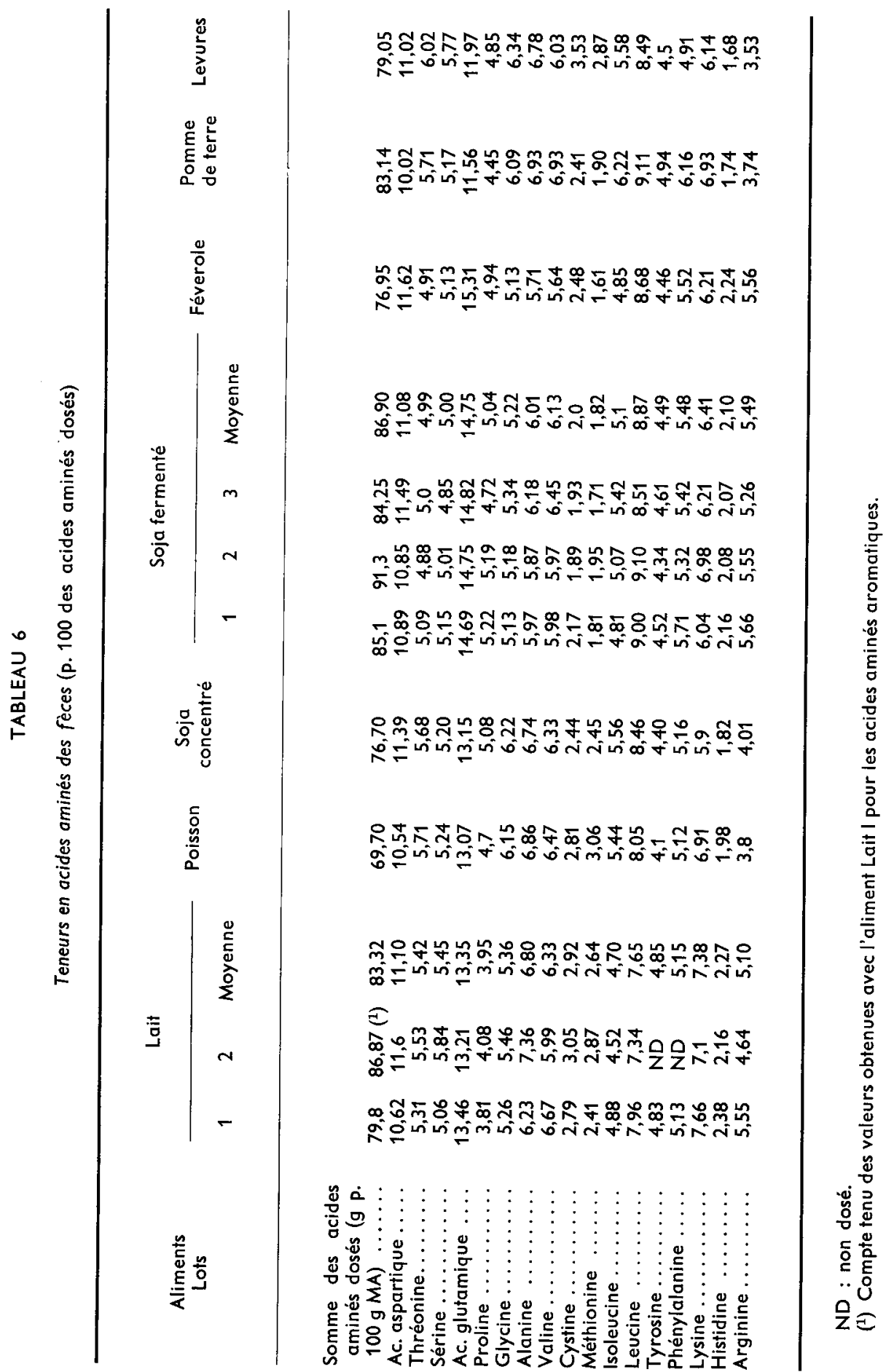


- Composition en acides aminés des protides fécaux.

La teneur en chaque acide aminé des matières azotées fécales est exprimée par le pourcentage qu'il représente dans la somme des acides aminés dosés de façon à éliminer l'influence de l'azołe non protidique sur les teneurs en acides aminés (tabl. 6).

La variabilité de la composition en acides aminés des fèces de veaux recevant le même aliment est réduite comme on peut le voir dans les fèces des veaux nourris avec les aliments Soja fermenté ou Lait.

Quelle que soit la nature des protéines alimentaires, les matières azotées fécales ont une composition en acides aminés relativement constante caractérisée par une forte teneur en cystine et dans une moindre mesure en thréonine, sérine, glycine et alanine ef une concentration assez basse en histidine. Cela pourrait indiquer qu'une fraction importante des protéines fécales a une origine commune, endogène et microbienne. Cependant, malgré les analogies qui viennent d'être soulignées, il est possible de distinguer 4 catégories de fèces par l'étude de l'écart relatif moyen (tabl. 7). La première est représentée par les protides fécaux de veaux nourris avec l'aliment Lait dont l'écart relatif moyen aux protides fécaux des veaux recevant les autres aliments est supérieur à 11 p. 100 (à l'exception de ceux des veaux recevant l'aliment Poisson) ; la seconde, par les protides fécaux des veaux nourris avec l'aliment Pomme de terre (écart relatif moyen supérieur à 9 p. 100) ; la troisième, par ceux des veaux recevant des aliments aussi différents que les aliments Poisson, Soja concentré et Levures. Quant à la quatrième, elle est constituée par les fèces des veaux nourris avec les aliments Soja fermenté et Féverole. Leur similitude de composition en acides aminés

\section{TABLEAU 7}

Comparaison $\left({ }^{1}\right)$ de la composition en ocides aminés des fèces entre elles $\left({ }^{2}\right)$ et à celle de l'aliment $\left({ }^{3}\right)$

\begin{tabular}{|c|c|c|c|c|c|c|c|}
\hline Aliments & Lait & Poisson & $\begin{array}{c}\text { Soja } \\
\text { concentré }\end{array}$ & $\begin{array}{c}\text { Soja } \\
\text { fermenté }\end{array}$ & Féverole & $\begin{array}{l}\text { Pomme } \\
\text { de_terre }\end{array}$ & Levures \\
\hline $\begin{array}{l}\text { Lait ............. } \\
\text { Poisson .......... } \\
\text { Soja concentré..... } \\
\text { Soja fermenté } \\
\text { Féverole ......... } \\
\text { Pomme de terre ... } \\
\text { Levures.......... }\end{array}$ & $\begin{array}{r}8,84 \\
11,06 \\
11,39 \\
12,89 \\
15,11 \\
12,29\end{array}$ & $\begin{array}{c}8,84 \\
5,70^{\mathrm{ab}} \\
13,11^{\mathrm{a}} \\
15,32^{\mathrm{bc}} \\
9,83 \\
6,62^{\mathrm{c}}\end{array}$ & $\begin{array}{c}11,06 \\
5,70^{\mathrm{a}} \\
\\
10,54 \\
12,94^{\mathrm{ab}} \\
9,66 \\
5,58^{\mathrm{b}}\end{array}$ & $\begin{array}{l}11,39^{\mathrm{a}} \\
13,11^{\mathrm{b}} \\
10,54 \\
3,85^{\mathrm{a} b c d} \\
13,61^{\mathrm{c}} \\
14,41^{\mathrm{d}}\end{array}$ & $\begin{array}{c}12,89^{\mathrm{a}} \\
15,32^{\mathrm{b}} \\
12,94^{\mathrm{c}} \\
3,85^{\mathrm{abcde}} \\
\\
16,78^{\mathrm{d}} \\
16,75^{\mathrm{e}}\end{array}$ & $\begin{array}{r}15,11 \\
9,83 \\
9,66 \\
13,61 \\
16,78 \\
10,61\end{array}$ & $\begin{array}{l}12,29 \\
6,62^{\mathrm{ab}} \\
5,58^{\mathrm{ed}} \\
14,41 \mathrm{ac} \\
16,75^{\mathrm{bd}} \\
10,61\end{array}$ \\
\hline Fèces, aliments $\left({ }^{3}\right) \ldots$ & $30,42^{\mathrm{abe}}$ & $15,7 \mathrm{a}$ & 21,96 & $16,13^{b}$ & 17,81 & $11,74^{\mathrm{c}}$ & 19,66 \\
\hline
\end{tabular}

(1) Ecart relatif moyen entre les protéine i et j :

$$
\frac{1}{16} \sum_{k=1}^{16} \frac{\sqrt{(A A i k-A A j k)^{2}}}{\text { AAik }+ \text { AAjk }}
$$

( $\left.{ }^{2}\right)$ Les valeurs affectées d'une même lettre dans la même colonne sont significativement différentes $(P<0,05)$.

$\left({ }^{2}\right)$ Les valeurs affectées d'une même lettre dans cette ligne sont significativement différentes $(P<0,05)$. 
(écart relatif moyen : 3,85 p. 100) met en évidence l'influence de l'origine des matières azotées alimentaires sur la composition en acides aminés des fèces puisque ces aliments contiennent des protéines de plantes de la même famille botanique dont les graines contiennent des glucides peu digestibles et des facteurs antitrypsiques. Cette influence est en partie masquée par les traitements technologiques. En effet, la composition en acides aminés des fèces des veaux nourris avec l'aliment Soja fermenté est plus éloignée de celle des fèces des animaux recevant l'aliment Soja concentré que de celle des fèces des veaux consommant l'aliment Féverole.

- Comparaison de la composition en acides aminés des protéines alimentaires et des protéines fécales (tabl. 7).

La composition en acides aminés des protéines fécales est très différente de celle des protéines alimentaires chez les veaux qui reçoivent l'aliment Lait. Cela pourrait indiquer que la digestibilité réelle des protéines et des acides aminés du lait est très élevée. Les protéines fécales seraient alors principalement constituées de protéines endogènes et microbiennes. Cela semble confirmé par la grande similitude de composition en acides aminés des protéines fécales des veaux nourris au lait et celle des protéines fécales de porcelets recevant un régime à 4 p. 100 de protéines d'œuf (Eggum, 1973) ou celles de porcelets ingérant un régime protéiprive (Pastuszewska, 1974) puisque les écarts relatifs moyens sont respectivement de 6,6 et 5,8 p. 100. L'écart relatif moyen entre la composition en acides aminés des protéines alimentaires et celle des protéines fécales des veaux ingérant les aliments Soja concentré ef Levures paraît assez important. En revanche, c'est dans le cas des veaux nourris avec l'aliment Pomme de terre que cet écart est le plus faible; une fraction plus importante de protéines fécales de ces animaux serait donc constituée de protéines alimentaires. L'écart relativement faible observé entre la composition en acides aminés de l'aliment Poisson et celle des fèces des veaux qui le consomment peut être dû à une perturbation de la digestion des matières azotées alimentaires chez un des veaux atteints d'une légère diarrhée (teneur en matière sèche des fèces inférieure à 12 p. 100) pendant 2 jours.

\section{- Origine des protéines fécales.}

Une autre technique utile à l'interprétation de la composition en acides aminés des fèces consiste à établir la régression de cette composition $(F)$ sur celle de la protéine alimentaire de remplacement $(A)$ et sur celle des fèces des veaux nourris avec l'aliment Lait $(B)$ de façon à tenter une estimation de la part respective des matières azotées d'origine alimentaire et d'origine endogène ef microbienne dans les matières zotées excrétées (tabl. 8). II convient toutefois d'être prudent pour interpréter les coefficients de la régression car il existe une corrélation élevée entre les variables $A$ et $B$. Cependant le coefficient de régression de la composition en acides aminés des fèces sur celle des matières azotées alimentaires de remplacement a varié en sens inverse de l'écart relatif moyen entre les compositions en acides aminés des protéines fécales et alimentaires. Cela confirme les remarques précédentes sur la forte digestibilité réelle des protéines des aliments Levures et Soja concentré, la digestibilité plus faible de celles des aliments Poisson puis Soja fermenté ef Féverole et surtout Pomme de terre. L'examen du coefficient $b$, toujours plus élevé que le coefficient $a$, indique que la fraction des 
matières azotées dont la composition en acides aminés est analogue à celle des fèces des veaux nourris avec l'aliment Lait est présente en quantité relativement importante dans les fèces de veaux quelle que soit la nature des protéines alimentaires. Cette fraction serait principalement constituée de protéines endogènes et microbiennes. En effet, elle est constamment présente de façon significative dans les fèces ; de plus, par sa composition en acides aminés, elle est analogue aux matières azotées fécales de veaux nourris avec l'aliment Lait qui sont pour la plupart des protéines endogènes et microbiennes puisque la digestibilité réelle des matière azotées du lait chez le Veau est très élevée (Roy ef al., 1970) et qu'elles ont une composition en acides aminés voisine de celle de fèces de porcelet recevant un régime à 4 p. 100 de protéines d'œuf (Eggum, 1973) ou un régime protéiprive (Pastuszewska et al., 1974).

\section{TABLEAU 8}

Régression $\mathbf{F}=\mathbf{a} \mathrm{A}+\mathrm{b} \mathbf{B}+\mathbf{K}$ de la composition en acides aminés des fèces $(F)$ sur celle de la protéine de remplacement $(A)$ et celle des fèces des veaux nourris au lait $(B)$.

Conséquences sur la réportition de l'azote fécal excrété pour $100 \mathrm{~g}$ d'azole ingéré

\begin{tabular}{|c|c|c|c|c|c|c|c|}
\hline Aliments & Lait & Poisson & $\begin{array}{c}\text { Soja } \\
\text { concentré }\end{array}$ & $\begin{array}{c}\text { Soja } \\
\text { fermenté }\end{array}$ & Féverole & $\begin{array}{l}\text { Pomme } \\
\text { de terre }\end{array}$ & Levures \\
\hline 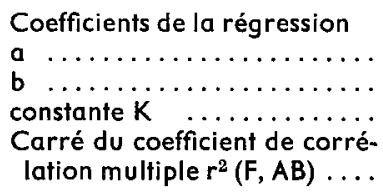 & $\begin{array}{l}\overline{-} \\
-\end{array}$ & $\begin{array}{c}0,159 \\
0,794 * * \\
-0,062 \\
0,961\end{array}$ & $\begin{array}{c}0,017 \\
0,970^{* *} \\
-0,087 \\
0,941\end{array}$ & $\begin{array}{r}0,295^{* *} \\
0,710^{* *} \\
-0,016 \\
0,978\end{array}$ & $\begin{array}{c}0,264^{* *} \\
0,786^{* *} \\
-0,324 \\
0,975\end{array}$ & $\begin{array}{l}0,424^{*} \\
0,496^{*} \\
0,472 \\
0,916\end{array}$ & $\begin{array}{c}-0,191 \\
1,115^{*} \\
0,414 \\
0,917\end{array}$ \\
\hline $\begin{array}{l}\text { Azote excrété p. } 100 \mathrm{~g} \text { d'azote } \\
\text { ingéré }(\mathrm{g}) \\
\text { Azote total } \ldots \ldots \ldots \ldots \ldots \ldots \\
\text { Azote des acides aminés dosés } \\
\text { Azote des acides aminés d'ori- } \\
\text { gine alimentaire............ } \\
\text { Azote des acides aminés d'ori- } \\
\text { gine endogène ou micro- } \\
\text { bienne }\left({ }^{1}\right) \ldots \ldots \ldots \ldots \ldots \ldots \\
\text { Azote non protidique }\left({ }^{(2)} \ldots \ldots\right.\end{array}$ & $\begin{array}{l}5\left(^{3}\right) \\
3,5 \\
-\end{array}$ & $\begin{array}{r}15,9 \\
9,1 \\
1,4\end{array}$ & $\begin{array}{r}16,6 \\
10,4 \\
0,2\end{array}$ & $\begin{array}{r}21,7 \\
15,8 \\
\\
4,7\end{array}$ & $\begin{array}{r}23,7 \\
15,2 \\
4,0\end{array}$ & $\begin{array}{r}13,9 \\
9,4 \\
4,0\end{array}$ & $\begin{array}{r}13,5 \\
8,7 \\
-\end{array}$ \\
\hline
\end{tabular}

* $P<0,05 ; * * P<0,01$ : probabilité pour que ces coefficients ne soient pas nuls. Lait.

${ }^{1}$ ) Azote des acides aminés de même origine que ceux des fèces des veaux nourris avec l'aliment

(2) Différence entre l'azote total et l'azote des acides aminés dosés.

(3) Valeur moyenne.

Etant donné que cette technique donne des résultats qui s'accordent avec ceux obtenus à l'aide de la comparaison des protéines fécales aux protéines alimentaires, cefte étude peut être complétée par une tentative de détermination de l'origine des matières azotées retrouvées dans les fèces. Elle peut être effectuée à partir de ces coefficients de régression, de la teneur en azote provenant des acides aminés des matières azotées fécales et de la quantité d'azote fécal excrété $\mathrm{p}$. $100 \mathrm{~g}$ d'azote ingéré (tabl. 8) compte tenu des réserves que nous avons émises sur la méthode. 
L'étude de la quantité d'azote fécal d'origine alimentaire excrété p. $100 \mathrm{~g}$ d'azote ingéré confirme les observations précédentes en indiquant que la digestibilité réelle des matières azotées serait très élevée pour les aliments Levures et Soja concentré, un peu inférieure pour l'aliment Poisson et encore plus faible pour les aliments Soja fermenté, Féverole ef Pomme de terre.

La quantité d'azote d'origine endogène et microbienne excrétée $\mathrm{p} .100 \mathrm{~g}$ d'azołe de l'aliment Lait ingérés est la plus faible. En revanche, elle est la plus élevée après ingestion des aliments Soja concentré, Soja fermenté et Féverole. Cela peut résulter de l'influence spécifique de certaines légumineuses sur l'excrétion d'azote métabolique fécale due en partie à la présence en quantités relativement importantes de glucides peu digestibles dans l'intestin grêle duVeau. Enfin, chez le Veau préruminant comme chez le Porc (Mason, Just ef Bech-Andersen, 1976), l'azote d'origine endogène ou microbienne représente une fraction considérable de l'azote excrété dans les fèces et ne dépend pas seulement de la quantité de matière sèche ingérée mais aussi de la source de protéines alimentaires.

\section{Conclusion.}

L'étude de la composition en acides aminés des fèces nous a permis d'une part de mettre en évidence une influence de la nature des matières azotées alimentaires sur leur utilisation digestive et d'autre part de souligner l'importance variable mais considérable des matières azotées endogènes et microbiennes dans les fèces (Fauconneau ef Michel, 1970) du Veau préruminant. Il semblerait qu'une meilleure connaissance de l'utilisation des protéines alimentaires pourrait être obtenue par l'étude des conienus d'iléon puisque c'est essentiellement dans l'intestin grêle que sont libérés et absorbés les acides aminés des protéines alimentaires. Dans le gros intestin, la présence de protéines endogènes et surtout les fermentations microbiennes atténuent l'influence des matières azotées alimentaires sur la composition en acides aminés des fèces (Holmes et al., 1975) et rendent plus difficile l'étude de l'utilisation digestive des protéines alimentaires. Mais il est aussi intéressant de connaître les effets de l'ingestion des aliments sur l'excrétion de matières azotées endogènes et sur les fermentations microbiennes. Dans ce cas, l'analyse des acides aminés fécaux peut être utile.

Accepté en juillet 1976.

Remerciements : Nous tenons à remercier Messieurs J. Prugnaud et J. Grizard de leur contribution respective au dosage des acides aminés ef à l'interprétation statistique des résultats.

\section{Références}

CARLSON K. H., BAYLEY H. S., 1970. Nitrogen and amino acids in the feces of young pigs receiving a protein-free diet and diets containing graded levels of soybean oil meal or casein. J. Nutr., 100,1353-1361.

COMBE E., 1973. Nitrogen metabolism in germfree rats. In HENEGHAN J. B. Germfree Research, 305-308. Academic Press. N. Y. 
DAMMERS J., 1964. Etudes sur l'alimentation du porc. Facteurs influençant la digestion des composantes alimentaires et la digestibilité des acides aminés. (en Hollandais). Inst. Veevoedingsonderzoek « Hoorn ». N. V. Drukkerij West-Friesland Hoorn. Pays-Bas.

DE MUELENAERE H. J. H., CHEN M. L., HARPER A. E., 1967. Assessment of factors influencing estimation of availability of threonine, isoleucine and valine in cereal product. J. agr. Food Chem., 15, 318-323.

EGGUM B. O., 1973. A study of certain factors influencing protein utilization in rats and pigs. Thèse Université royale vétérinaire ef agricole, Copenhague.

FAUCONNEAU G., MICHEL M. C., 1970. The role of the gastrointestinal tract in the regulation of protein metabolism. In MUNRO H. N., Mammalian Protein Metabolism, vol. 4, 481-522. Academic Press N.-Y.

GUILLOTEAU P., TOULLEC R., CULIOLI J., LE DOUARON D., 1976. Utilisation des protéines par le Veau préruminant à l'engrais. IV Utilisation digestive des protéines du poisson, du soja et de la féverole. Ann. Zootech., 25 (sous presse).

HEPBURN F. N., CALHOUN W. K., BRADLEY W. B., 1966. The biological availability of essential amino acids in wheat, flour, bread and gluten. Cereal Chem., 43, 271-283.

HOLMES J. H. G., BAYLEY H. S., LEADBEATER P. A., HORNEY F. D., 1974. Digestion of protein in small and large intestine of the pig. Br. J. Nutr., 32, 479-489.

KUIKEN K. A., LYMAN C. M., 1948. Availability of amino acids in some foods. J. Nutr., 36, 359-368.

MASON V. C., JUST A., BECH-ANDERSEN S., 1976. Bacterial activity in the hind-gut of pigs. 2 . Its influence on the apparent digestibility of nitrogen and amino acids. Z. Tierphysiol. Tierernährg. u. Futfermitfelkunde, 36, 310-324.

PASTUSZEWSKA B., DUEE P. H., HENRY Y., BOURDON D., JUNG J., 1974. Utilisation de la féverole entière et décortiquée par le porc en croissance : digestibiliłé et disponibilité des acides aminés. Ann. Zootech., 23, 537-554.

PION R., FAUCONNEAU G., 1966. Les acides aminés des protéines alimentaires. Méthodes de dosage et résultats obtenus. In Amino Acides, peptides, protéines. Cahier no 6, 159-175. A.E.C. Société de Chimie Organique et Biologie. Commentry.

PION R., MENDES-PEREIRA E., PRUGNAUD J., 1974. Composition en acides aminés ef valeur nutritive de quelques nouveaux aliments protéiques. Deuxième Symposium Alimentation et Travail. Vittel, mai 1974.

POPPE S., MEIER H., UHLEMANN H., 1971. Untersuchungen über die Aminosauren Resorption aus verschiedenen Proteinträgern bei Ratten. Arch. Tierernährung, 21, 161-170.

POPPE S., MEJER H., WIESEMULLER W., 1970. Untersuchungen über die Aminosauren-Resorption aus verschiedenen Proteinträgern beim Schwein. Arch. Tierernährung, 20, 575-582.

RADOSTITS O. M., BELL J. M., 1968. Nutrient digestibility by new-born calves fed milk replacer. Can. J. Anim. Sci., 48, 293-302.

ROY J. H. B., STOBO I. J. F., GASTON H. J., 1970. The nutrition of the veal calf. 2. The effect of different levels of protein and fat in milk substitute diets. Br. J. Nutr., 24, 441-457.

SNEDECOR G.W., COCHRANW. G., 1971. Méthodes statistiques. Association de coordination technique agricole. Paris.

TOULleC R., PATUREAU-MIRAND P., PARUELLE J.-L., GUILHERMET R., 1973. Utilisation des protéines par le Veau préruminant à l'engrais. Bull. Soc. Sci. Hyg. Alim., 61, 57-92.

TOULLEC R., PATUREAU-MIRAND P., THIVEND P., VERMOREL M., 1975. Bases physiologiques de la réalisation des aliments d'allaitement pour veaux. Bull. Soc. Sci. Hyg. Alim., 63, 69-100.

VAN WEERDEN E. J., 1974. Low fat fish meal in milk replacers. In Third european symposium on the use of fish meal in animal feeding. Amsterdam 11-12 septembre 1974. I.A.F.M.M. Potters Bar. Grande-Bretagne 96-111. 